\title{
Building a Strong Foundation for Occupational Health and Safety: Action Research in the Workplace
}

\author{
Judith A. Daltuva, MSW, MA, ${ }^{1 *}{ }^{\dagger}$ Katherine R. King, PE, BCEE, MS, ${ }^{2}$ \\ Melina K. Williams, MPH, JD, ${ }^{2}$ and Thomas G. Robins, $\mathrm{MD}, \mathrm{MPH}^{3}$
}

Background Action research (AR) holds promise as a method to improve occupational health and safety.

Methods This case study explores the challenges and accomplishments during the first 6 months of an AR occupational health and safety committee at a manufacturing facility. Results Critical steps in the formative phase of the AR project included: (1) addressing differing power levels and perceived ownership of management and production committee members; (2) developing a collaborative approach to communication and problem solving; and (3) transitioning from dependence on university leadership to shared leadership among the committee.

Conclusions $A R$ can lead to greater empowerment to address occupational health and safety issues, and to improved dialoge between labor and management. AR can increase the likelihood that the problem will be understood, and effective solutions will be developed and their application supported and used throughout the organization. Am. J. Ind. Med. 52:614-624, 2009. ๑ 2009 Wiley-Liss, Inc.

KEY WORDS: action research; participatory; occupational health and safety; joint union management collaboration; empowerment

\section{INTRODUCTION}

\section{Background}

Industrial workers face numerous hazards on the job that may put them at risk for occupational illness and

${ }^{1}$ Environmental Health Sciences, University of Michigan School of Public Health, M6234 SPH II, Ann Arbor, Michigan

${ }^{2}$ Environmental Health Sciences, University of Michigan School of Public Health, M6168 SPH II, Ann Arbor, Michigan

${ }^{3}$ M6007 SPH II, Ann Arbor, Michigan

†Project Manager.

*Research Associate

Contract grant sponsor: National Institute of Environmental and Health Sciences; Contract grant number: 5 U45 ES006180-16.

*Correspondence to: Judith A. Daltuva, M6234 SPH II, 1420 Washington Heights, Ann Arbor, Ml 48109-2029.E-mail: jdal@umich.edu

Accepted 14 April 2009

DOI 10.1002/ajim.20711. Published online in Wiley InterScience

(www.interscience.wiley.com) injury. The critical role of worker education in promoting occupational health and safety has been recognized for many years [Hughes, 1991; Wallerstein and Weinger, 1992; McQuiston et al., 1994; McQuiston, 2000; Occupational Safety and Health Administration, 2003]. Historically, such training programs usually have been entirely under management control and have focused on changing workers' behaviors to promote health and safety. More recently, there has been increasing recognition of and emphasis on training methods that recognize workers as change agents able to address root causes of occupational illnesses and injuries [Fernandez et al., 2000; Lippin et al., 2000; Kowalski et al., 2008]. There has also been increasing development and use of participant-centered training methodologies that focus on groups of workers solving health and safety problems together [Kurtz et al., 1997; Fernandez et al., 2000; Lippin et al., 2000; Kowalski et al., 2008].

Such training typically will address methods of hazard identification, remediation, and engagement of management 
in the process of ameliorating health and safety conditions. This approach has been especially well-developed in the United States among a group of union- and universitybased consortia funded by the National Institute for Environmental Health Sciences (NIEHS) under the OSHA Hazardous Waste Operations Response Standard (OSHA 29 CFR 1910.120) as part of the Worker Education and Training Program (WETP). This participant-centered, worker-empowering approach has come to be recognized as one of the most important components of a preventive program in occupational health and safety [Wallerstein and Weinger, 1992; McQuiston et al., 1994; Kurtz et al., 1997; McQuiston, 2000].

In keeping with this emphasis on participatory methods, for over 18 years the University of Michigan School of Public Health Hazardous Materials Evaluation Project (UM) and the Health and Safety Department of the International Union of the United Automobile, Agricultural Implement, and Aerospace Workers (UAW) have engaged in collaborative worker education and training research. In 1990, the UAW was awarded a continuing grant from NIEHS to provide health and safety training programs designed to educate union members and supervisory personnel in the prevention, recognition, and control of incidents involving hazardous materials in the workplace.

Earlier research demonstrated that joint union and management action strengthened organizational health and safety efforts [University of Michigan Evaluation Group, 1992, 1995; Schurman and Israel, 1995]. In order to test the expected benefits of longer term joint projects that involved researchers as evaluators and change agents, UM researchers planned a 3-year action research (AR) project at a single manufacturing facility with support from the UAW Health and Safety Department and funded under the NIEHS grant.

\section{AR: Definition and Rationale}

$\mathrm{AR}$ is a cyclical problem-solving process that joins researchers and research participants in a cooperative endeavor with the tandem goals of generating knowledge and effecting change. Methodologies involving AR offer many benefits for applied research in organizations such as the emphasis placed on problem solving [Elden, 1981; Whyte, 1991; Israel et al., 1992; Bradbury et al., 2008].

AR differs fundamentally from basic social science research in its purposes and the respective roles played by researchers and research participants [Israel et al., 1992; Reason and Bradbury, 2001]. Collaboration is central to AR, with researchers and participants acting as co-learners [Elden, 1981; Bradbury et al., 2008].

AR proceeds by a series of iterative steps: identify an issue of concern, collect and analyze data, develop and take action on solutions, evaluate the process and intervention, and then repeat the steps. All participants are involved in all AR research activities and have influence over each of these steps [Elden, 1981; Israel et al., 1992; Bradbury et al., 2008].

Several considerations drove the choice of $\mathrm{AR}$ as a valuable technique for this setting. Firstly, AR offered a comprehensive way of dealing with occupational health and safety issues [Elden, 1981; Israel et al., 1992]. Furthermore, it facilitated skill development among workers helping to ensure long-term sustainability of safe workplace systems [Elden, 1981; Israel et al., 1992]. AR also meshed well with the underlying principles of the UAW program, which emphasized empowerment of hourly production workers to collectively solve health and safety problems. Finally, because of the power and equity issues involved, AR presented a possible vehicle to address this inequity and to improve relationships among union and management [Gaventa and Cornwall, 2008]. Many observers [Simon, 2006] have noticed a clear pattern of decreasing power of workers in the US. This is reflected in a steady and substantial drop in the percent of the workforce belonging to a union. By 1983 the union membership rate was $20.1 \%$ and the most recent reports from the US Department of Labor, Bureau of Labor Statistics (2007) indicate only $12.0 \%$ of the workforce belong to a union. Labor often is a disempowered actor within a corporate structure, where the primary focus is on profitability for the corporation. The union can be considered in principle as a collective voice of labor, intended to influence management decisions that involve the protection of the health and welfare of its members. Although it can be argued that cooperative relationships are of benefit to both union and management, there exists an ever present tension between conflicting fundamental interests and purposes.

This work builds on a long international tradition of $\mathrm{AR}$, democratization of working life, and participatory approaches to promoting workers' health [Elden, 1981; Gardell, 1982; Laurell et al., 1992]. Much has been written about the application of these methodologies to address psychosocial issues at work [Gardell and Gustavsen, 1980; Israel et al., 1989; Svensson, 1991; Parkes and Sparkes, 1998; Mikkelsen et al., 2000; Mikkelsen and Gundersen, 2003; Bourbaonnais et al., 2006; Dollard et al., 2007]. However, the application of AR to occupational health and safety issues related to workplace chemical and physical hazards and the processes involved in establishing such an AR project have not been as extensively covered in the literature. This case study of the application of AR as a method to systematically address occupational health and safety issues in an organized workplace examines the crucial formative phase of AR needed to establish a solid foundation on which to build [Israel et al., 1989; Schurman and Israel, 1995; Schulz et al., 2003]. Lessons are drawn that may be of significance to business and labor leaders and researchers interested in using AR. 


\section{RESEARCH DESIGN AND METHODS}

\section{Research Goals and Objectives}

The University of Michigan research team (hereafter, UM researchers) entered into this project with a broad set of research goals set forth in the language of the subcontract in the initial grant proposal to NIEHS. These included: Goal 1 improves the decision-making process for health and safety; Goal 2 enhances empowerment of workers and their local union; Goal 3 improves health and safety conditions; Goal 4 evaluates and documents the impacts of the process. An additional, unstated goal of the UM researchers was to assist in changing of workplace culture toward an increased emphasis on health and safety issues. Although ideally the goals and objectives of an AR project would be developed through involvement of all AR project participants, in this case the broad goal of using an AR approach had already been adopted by the UM research team in the funding proposal. The UM researchers believed that presenting a pre-defined AR approach to prospective participants would result in an increase in the level of interest and a willingness to participate in the project. This article reports on the formative period of the AR process and progress toward attainment of Goals 1, 2, and 4. Goal 3 was expected to require progress over a longer time frame than the initial 6-month period covered in this article.

This case study involves an AR project to improve worker health and safety at a manufacturing facility in northwestern Ohio. The University of Michigan (UM) and local union and management representatives engaged in this research with assistance from the UAW International Health and Safety Department with the overarching goal of placing all participants on equal footing when dealing with health and safety issues.

\section{Site Identification and Selection}

In keeping with the guidelines set forth in the grant proposal, UM researchers developed four primary criteria: (1) a UAW-represented facility with a well-established joint union and management health and safety committee, which was expected to be indicative of a positive working relationship between labor and management on health and safety issues; (2) a significant use of potentially hazardous chemicals at the facility; (3) an agreement from management to conduct training on chemical hazards and emergencies (a requirement of the NIEHS grant funding the project); and (4) substantial commitment to the project from plant management and local union leadership. Five additional facility characteristics were also considered desirable: (1) a stable business climate; (2) stable leadership; (3) an employee population between 300 and 1,200 (smaller facilities might not have sufficient flexibility in the job duties of involved personnel, and larger facilities might have organizational structures more resistant to change); (4) a diverse workforce; and (5) a location within reasonable travel distance from the University of Michigan in Ann Arbor, Michigan.

With assistance from the UAW, UM researchers compiled a list of 479 potential sites. Of these, 434 were eliminated because of concerns regarding size or distance. UM researchers gathered information from and explored the level of interest with the management and/or union leadership of the remaining 45 sites by telephone. UM selected and visited seven sites based on level of interest in the AR model. During the site visits, UM researchers made it clear that several sites were being considered and that only one site could participate. Two facilities withdrew from consideration because they could not make the time commitment needed for an AR project. Of the remaining plants, one was a relatively small privately held corporation, with the rest being part of a large international corporation. The smaller plant was eventually selected because of management's openness to and enthusiasm for the AR process in their facility. This facility was also flexible regarding the starting date for the project, whereas other plants could not commit the necessary resources to the project for several months due to production demands and upcoming union negotiations. The original goals included finding a diverse work site, but it was not possible to meet all criteria. The selected plant employed a low percentage of African American and Hispanic workers. Eighty-five percent of the shop floor employees were male and $15 \%$ were female.

\section{Protection of Human Subjects}

The University of Michigan Institutional Review Board for Health Sciences Research approved the study methods and informed consent form. Participants on the facility AR committee signed informed consent forms. As discussed in greater detail below, at the committee's request, participants who completed the plant-wide survey remained anonymous to encourage open and honest responses. Therefore, they were not asked to sign informed consent forms.

\section{Site Characteristics}

The participating facility was an automotive independent parts supplier (IPS) in northwestern Ohio. It employed $\sim 300$ workers and consisted of two plants located across the street from each other. The two plants had separate plant leaders (similar to a plant manager) but shared a common Chief Executive Officer.

Although a single, joint labor management health and safety committee that represented both plants already existed, information provided from informal discussions with plant employees indicated that it was not viewed as 
effective. To a large extent, health and safety was considered more to be the responsibility of a very small Human Resources (HR) Department, rather than this committee. All parties agreed that an active joint union management committee needed to be established as part of this project to replace the existing committee.

\section{AR Initial Planning Meetings and Committee Selection}

Following agreement among UM researchers, management, and local union leadership to proceed at this site, an initial planning meeting was held. The meeting was attended by key representatives selected by union and management at the plant, as well as representatives from UM and the UAW International Union Health and Safety staff. This meeting established an agreement to carry out the AR project at the site. A second meeting was held $\sim 2$ months later with a somewhat broader representation of local union and management attendees selected by those who attended the first meeting.

During the second meeting, the question of the composition of the AR committee was raised among the attendees. Those present discussed desired membership criteria such as existing roles in the union and management structure, knowledge of health and safety, equal representation from each plant and the need for decision-makers on the committee. On this basis, 12 individuals either volunteered or were nominated by others and agreed to serve. The make-up of the committee was representative of the shop floor population. Notably, the thusly constituted AR committee intentionally included equal numbers of salaried and hourly employees and included personnel with key health and safety responsibilities (i.e., plant leaders and union health and safety representatives from both plants), representatives from two of the three work shifts, and the HR manager. The Vice-President for Human Resources and the union president attended the first two planning meetings, but chose not to be members of the final committee, stating that they wanted to give others a chance to participate.

The process by which this project was initiated created a tension between a UM defined set of goals (under the grant) and the intention that this evolve into true AR where all members participate equally. UM staff believed that they were bringing a vision of an egalitarian approach to decisionmaking substantially different from that practiced in most manufacturing facilities. As one UM researcher stated, "We are imposing a process on this plant; it is a participatory process, but it is still being imposed." With AR, the UM researchers hoped to move the group from typical decisionmaking processes in which management is virtually in full control to one in which hourly workers in the group have a truly equal voice. The hope was that the group would develop a method that would respect and honor the opinions of all its members when addressing issues and when engaging in the research process. Based on observations at other similar facilities, the UM-based researchers believed it was exceedingly unlikely that individuals at this site would invent this approach to decision-making, because it was outside the traditional cultural bounds practiced in the facility and in the US automobile industry at the time. UM hoped that the merit of these approaches would come to be recognized by the group and adopted with modifications to accommodate the specific circumstances in the plant.

As mentioned earlier, UM researchers' activities were supported by external funding. This meant external accountabilities were necessary, including the need to evaluate the effectiveness of using this method in promoting a safer workplace. In order to accomplish this, the researchers believed it important to collect "baseline" information near the beginning of the study, in order to document any changes that might occur over the life of the program. A decision was made to conduct a survey, in view of the UM PI's advocacy of a broad survey of the plant population as an efficient and wellestablished method of baseline data collection. The survey (discussed in more detail in the Results Section) addressed the organizational safety climate, personal empowerment to address health and safety concerns, general health and safety awareness and concerns, perceptions of health and safety conditions on specific jobs and throughout the plant, and union and management roles and attitudes in addressing health and safety.

In addition to the survey, the UM researchers used a variety of qualitative data collection methods over the first 6 months of the project to document the project's development over time. Sources of data upon which the results described below are based included the following: detailed field notes taken by UM researchers at each committee meeting, which primarily included a record of what was said, group interactions, room arrangement, and reflections on the meeting; meeting minutes, which recorded the main points and decisions of each meeting; notes from discussions among UM researchers following each meeting; additional field notes from informal conversations with plant personnel during tours of the shop floor; and notes from unstructured individual interviews with key plant personnel conducted by UM researchers prior to the launch of the project. The unstructured interviews and informal conversations conducted prior to and during the launch of the project explored: how decisions are made at the facility, concerns about suboptimal health and safety work environments and procedures, areas of the plant with specific occupational health and safety problems, and how AR would fit into the plant's organizational decision-making structure.

In a process which followed recommended methods from qualitative research [Ryan and Bernard, 2000], two members of the research team independently read through the materials making notations about relevant themes and 
key findings. The UM researchers took responsibility for developing and extracting information from these sources to prepare this manuscript. The text was written by the UM researchers and then circulated to the entire committee for review and comment. Although recognizing that a longer term goal was the involvement of the committee members in all aspects of the evaluation, UM researchers chose to do this early evaluation task on their own as the committee members did not have strong backgrounds in this type of research. Further, the UM researchers believed that, although management members would have flexible time and resources available for this type of activity, equal participation of the union members would be difficult to achieve due to constraints on time and resources. Moreover, during the initial 6 months, the members simply had not cohered enough as a group to carry out such an evaluation activity. Any discrepancies or questions raised by the entire committee were addressed through appropriate modifications of the manuscript as indicated.

\section{RESULTS}

\section{Overview}

The following section describes the processes and activities during the initial phase to address occupational health and safety issues in the facility. The discussion of the initial meetings and development of the group process addresses movement toward attainment of Goal 1, improving the decision-making process for health and safety. The discussion on changes in group dynamics addresses attainment of Goal 2, enhancing empowerment of hourly workers and local union. The discussion of gathering information highlights early actions taken by the committee toward ownership of issues and takes into account both Goals 2 and 4 , evaluating and documenting the impacts of the process.

\section{Initial Meetings and Development of Group Process}

From the outset, both union and management personnel at the plant showed willingness to engage in the research process. Management and shop floor employees at this facility had been working with several consulting groups on issues such as team building, consensus decisionmaking approaches, and communication. During the initial discussions prior to plant selection, one of the UM researchers' key management contacts, the Vice-President for Human Resources, stated that he thought the philosophy of AR fit well with what they were trying to do in the plant. He said it would help with communication and feedback to employees, which he listed as major concerns at the plant. The long-term nature of the project also offered more continuity than had the previous work with consultants. The union president expressed similar views and added that AR offered the opportunity to build relationships and skills and to develop and implement solutions that would, in the long run, result in a healthier and safer workplace.

The facility was new to using a diverse, multistakeholder collaborative approach to problem solving in addressing occupational health and safety. Consistent with prior research by others on participatory and collaborative processes, the first several months of a new collaboration were characterized by activities and discussions that focused on building and sustaining trust among committee members, such as:

- identifying a clear vision of purpose and objectives;

- developing ground rules to moderate power differences;

- sharing meeting facilitation and project workload;

- engaging in behaviors that defended equal ownership of ideas and projects; and

- conducting small-scale activities with high inherent probability of success that helped build an understanding of issues and multiple perspectives [Vangen and Huxham, 2003].

The first meeting of the AR committee took place $\sim 1$ month after the second planning meeting. During this meeting, the committee set forth broad goals regarding health and safety issues in the plant, defined structural norms and rules for decision-making, and decided on a meeting schedule. In addition, the committee agreed that any "outside" discussions of meeting proceedings would avoid attribution of comments or ideas to specific individuals.

The group met $2 \mathrm{hr}$ twice each month throughout the first 6 months. Between 2 and 4 UM researchers attended each meeting. For the first 3 months of the project the UM researchers facilitated, took field notes, and prepared minutes. The committee decided that all employees should have access to the information from the meetings, so the minutes from each meeting were publicly posted at the facility.

Developing effective group processes is essential to meeting the objectives of AR [Schulz et al., 2003]. In an effort to address the range of committee members' experience with formalized group process, early meetings focused predominately on group process. Some members expressed frustration with this approach, perceiving the committee as being slow to address health and safety problems concretely. One of the union members explained that there "seemed to be an understanding that you ladies [all of the UM researchers that regularly attended the meeting were female] would take us by the hand and drag us into training. Then we took another look at the letter [a sheet handed out at the orientation explaining the steps of AR] and it makes it clear that's not where we get training, it says it's all up to us." Another added that "we're the ones who are 
driving the process and we're the people who should be involved, we're here and won't go away [as UM researchers eventually will]."

Early in the AR process, the committee identified two general areas of focus: (1) elimination of conditions in the plant that did not comply with health and safety policies and standards; and (2) provision of health and safety training for plant employees. Some committee members also considered it important to share the achievements of the committee with all plant employees. Union members expressed the importance of demonstrating that the release time they were given was being spent in a productive manner.

After discussing the committee's scope and potential impact, a subcommittee composed of the two plant leaders and one of the union representatives drafted a mission statement. The final wording, approved by the entire committee, read: "Use a team approach to develop an environment to eliminate or prevent non-conforming health and safety conditions through a continuous improvement process."

\section{Changes in Group Dynamics}

The UM researchers set the agenda for the first few meetings, after which the committee discussed and set the agenda at the end of each meeting. Initially, the plant leaders and HR representative spoke much more frequently than other committee members at the meetings. Most hourly production members were not accustomed to meeting with management; they had had very little role in key decisionmaking in the plant. Most initially did not enter into discussions, and several physically sat back from the table. In an effort to increase participation, UM researchers often divided the group into pairs for discussion of specific topics.

Originally, UM researchers facilitated the entire meeting. Later the researchers asked for volunteers from the group. The first members of the group to volunteer to facilitate were management representatives. All members, including those who had no prior facilitation experience eventually agreed to participate in this role. A couple of the hourly members who indicated that they were not comfortable in the role of facilitator requested assistance from the UM researchers, who then provided coaching on facilitation techniques. UM researchers also supplied written materials on running meetings to a few of the members who requested them. One of the hourly production workers stated that he liked orderly meetings and so when he took his turn at facilitation he used Robert's Rules of Order, just as he did when running his local raccoon hunting association. Unlike the initial meetings where the group considered it to be the UM researchers' meeting, if the UM researchers wanted time on the agenda they had to make a request in advance. By the end of the first 6 months, facilitation responsibilities had transferred almost entirely to the group.

The hourly workers who had more history and comfort with public speaking and running meetings became involved first, easing the subsequent transition of hourly workers without such experience. In addition, there was a perception on the part of the union members that this committee had the potential to do important things, and since they were the people who were in the plant and had the expectation of continuing to be in the plant on a daily basis, they had a better idea of their direction and aims than did the UM researchers. This may well have been an inadvertent though desirable product of the UM researchers inexperience with AR in that they were overly directive at first, which led to the in-plant group members wanting more of a say in the pace and action of the group.

One of the first issues that the AR group chose to address was acute trauma (accidents) in the plant. A subcommittee of three union representatives and a representative from HR formed to collect and review data to determine when and where accidents occurred and to look for trends in accidents over time. Members of this subcommittee also conducted short informal discussions with a convenience sample of shop floor employees to determine their health and safety concerns. This process helped the committee identify important areas in the plant that needed attention. Similar to findings of prior research by others, identification of and action on modest size, low-risk issues early in the collaborative process reinforced the added value of a multistakeholder approach to addressing facility issues [Lawrence et al., 1999; Vangen and Huxham, 2003].

Another early achievement of the AR committee was the promotion of health and safety training. Three months after its formation, the committee played an instrumental role in arranging for the Health and Safety staff of the UAW International Union to conduct plant-wide OSHA Hazard Communication (HAZCOM) training, sometimes referred to as "Right to Know" training, for all employees over a 3-day period. There had been many new hires since the previous training and so committee members viewed simply holding the program as a success, a perception that was further strengthened by the high participation rate (222 union and salaried workers attending, $78 \%$ of workforce) and positive reception.

\section{Gathering Information}

The HAZCOM training was viewed by the UM researchers as an excellent opportunity for the AR committee to gather baseline data using a survey instrument. The PI particularly was concerned about gathering information about the state of the plant, general climate, health and safety conditions, and attitudes regarding health and safety issues in the plant. It was also argued by some of the UM researchers 
that these data would be valuable to the AR committee as it would provide baseline data upon which successes of the committee could be demonstrated.

At about the same time, some of the plant management were concerned about moving forward quickly on the HAZCOM training in the plant. A few months before this plant was selected, the UAW H\&S Department was contacted about doing the training and a date was set but then rescheduled until the AR project was up and running. At this point another reason for collecting information was introduced, that documenting the current health and safety situation would show whether the training intervention influenced health and safety conditions in the plant. This information would be useful since funding for the project was provided by a training grant. Because of the insistence of the UM researchers on meeting this timetable, there was no opportunity for such a commitment to rise organically through full participation of the group. From this point forward collection of baseline data became linked to the HAZCOM training program.

In retrospect, it became clear that most members of the group did not feel ownership of the data collection instrument and, consequently tended to discount the results of the survey. The AR group thought that the employees on the shop floor did not know of the group's involvement with the survey and suggested that the respondents did not take the questions seriously. They stated that the survey was just a "scratch session" or that people "just circled down the middle without even reading the questions." Members of the group were so concerned about the believability of the results that they offered to administer the questions or a subset of the questions to everyone in the plant again to find out the "real answers." This response clearly indicates the importance of jointly developing and implementing data collection strategies, so that all parties believe and accept the results. As Israel et al. [1992, p. 88] noted, "Particularly within an AR project it is necessary that participants understand and 'own' the data." It also illustrates the importance of the presentation of data collection activities to those filling out the forms. While questions about the credibility of survey data could not be resolved definitively, it is of interest that standard review by UM researchers of survey response choice patterns revealed little evidence of arbitrary answers by survey respondents.

Despite the initial disparaging perspectives of the survey results, the committee members eventually listed sponsoring a HAZCOM training for all employees (which brought the company into compliance with OSHA regulations) and collecting plant-wide survey data among their initial successes. They also included increasing health and safety awareness among committee members as well as among management and union employees; and forming an ergonomics subcommittee.
In the area of ergonomics, the committee created facility maps of sites where musculoskeletal injuries occurred, examined the causes of these injuries, made recommendations for necessary ergonomic improvements, and arranged for ergonomics awareness training for the AR group. In terms of process-based changes that occurred within the group, members' increasing comfort with each other and experience with the group led to wide participation in open discussions on these issues.

\section{DISCUSSION}

\section{Challenges}

The first 6 months of this occupational health and safety AR project reported here marked the formative period for this group. Along with the accomplishments listed above, the AR committee also encountered a number of challenges. Four key challenges faced during this formative phase were: (1) achieving a balance between research, action, and group process; (2) implementing a participatory, democratic process in a historically hierarchical organizational setting; (3) defining and agreeing upon roles; and (4) maintaining a primary focus on hazardous chemicals. UM researchers faced the additional initial challenge of finding an appropriate site for the research project. Each of these is addressed below.

On the first point, a persistent three-way tension existed between action, research, and participatory processes. For example, some members of the AR committee had the desire to "get out on the floor and fix problems" while others were more inclined to collect information prior to taking action. Representatives from both union and management expressed frustration at what they saw as the slow pace of progress on tangible changes in the plant while others believed the foundation for action had to be established through participatory group processes such as creating group norms. One member compared the production environment with that of the university with the remark, "Quite frankly, we are not in an academic environment where we can just sit back and think about things. We need to show movement." This tension appeared to decrease when the group began to see more tangible successes which were directly relevant to conditions in the plant. One example of a success was the Hazard Communication training for the entire plant, and another, the provision of chairs for workers in a particular job setting as a solution to ergonomic concerns. In terms of the perceptions of workers and managers who were not part of the committee, these kinds of successes were visible and could be appreciated, whereas the setting of norms and consensus building within the committee remained invisible to those outside the committee setting. Most group members, upon reflection later in the life of the committee, acknowledged the importance of emphasizing 
group process early in the initial months to lay the foundation for later work.

It appeared that lack of practice and familiarity with the conduct of AR led the UM researchers to put too much emphasis on the research concept of having baseline data. Time pressures also complicated the relationship between action, research, and group process as lack of time may have led to compromises in the participatory process. Although the AR group provided some input and also assisted in writing a few of the questions, most committee members considered the survey to be a creation of UM researchers. In retrospect, more innovative solutions to this tension should have been sought.

On the second challenge, both the union and the management structures in the facility relied on very uneven power relations. Generally, hourly production union employees had little or no involvement in decision-making. The ultimate power for almost all decisions about the organization of work, where to spend resources, and how to market products rested with management. While the union and hourly workers already had some limited input into the area of health and safety practices, long-term solutions to many issues in this arena are dependent upon capital improvements and reorganization of work, for example, improved ventilation and enclosure of operations emitting hazardous substances into the air. Management in general did not tend to view health and safety improvements as an investment in resources that contributed to overall effectiveness and morale of the organization. Instead, health and safety was seen by management as an ancillary issue to production which usually received attention only around negative consequences or aspects. Stated differently, health and safety issues get attention through grievance procedures, when injury rates cause an increase in worker compensation or insurance costs, or when a fatality occurs.

The AR process was intended to encourage full participation of all committee members on more equal footing in terms of power. The process was successful in bringing union and management closer to a level playing field. The union did not appear to be suspicious of management's motives for participating in this project; on the contrary, as time progressed, most union members of the group became increasingly eager to vocalize their ideas in health and safety with the expectation that their suggestions would lead to important tangible changes in the workplace. It was clear that the increased sharing of power within the committee was a significant change from the usual plant culture and would not have occurred without the ideas brought into the plant by the UM research team.

The UM researchers brought their own perspectives to the research project, and it is important to examine their role in the power dynamics within the AR process at this facility. At the beginning of the study, substantial influence resided within the UM team in that they were seen as bringing expertise in AR and meeting facilitation, skills unfamiliar to most of the AR committee. The impact of these power differences emerged early in the AR process, as evidenced by the agreement of the committee to go forward with the conduct of a baseline survey, initiated and encouraged by the UM team, despite the lack of ownership by most of the committee of this approach and the survey instrument. It is unclear what role gender differences (the University group was predominantly female) played in these early dynamics. Until members of the committee became more familiar with each other, male members appeared reluctant to openly disagree with "the ladies." These power differences soon lessened as the plant-based committee members became more comfortable with the AR process and took greater control over the facilitation of the meetings.

The group also encountered the challenge of defining and agreeing upon roles, which was especially an issue with the roles of the UM researchers. Not only were there disagreements among the UM researchers about how directive they should be, but also about how directive they were being in practice. The initial lead UM research team member tended to advocate being more directive than the other members of the team. Although she often perceived herself as being minimally directive, others in the AR group perceived her as overly directive. She also advocated a longer transition period between UM researchers serving in a more facilitative capacity to the UM researchers becoming equal participants with shared power in the group.

The UM research team members lacked practical experience implementing AR projects. In addition, they were not familiar with working with each other and also were not sufficiently oriented to the methods intended because they had not experienced the entire process from the initial decision to conduct an AR project, through the selection of a site for the project, to the actual launch of the project. There had been a complete turnover in the research staff prior to the actual launch of the project, with the exception of the PI, whose intended and actual role was more as a resource with occasional interaction with the plant rather than that of an active participant.

Facility-based members of the committee also held varying views on the involvement they desired from UM researchers. In the initial phase they referred to the committee meetings simply as the UM meetings. At that time, many committee members looked to UM researchers as technical experts and viewed the AR project as being "owned" by them. One of the members asked "Why don't you ladies just go out there on the floor and fix it?" As members of the group had more opportunities to take on new responsibilities, they gained confidence and came to see the UM researchers more as equal members of the group where the plant members and the UM researchers brought different skills to the process. The members also adopted a name that incorporated the name of the facility along with that of UM. 
The fourth challenge regarded the apparent conflict between the committee's focus and the focus of the funding agency grant guidelines on chemical-related health and safety issues. Although this facility had serious issues related to chemical hazards, and the committee had initially agreed to concentrate on hazardous chemicals, these issues did not become prominent during the first 6 months of the committee's existence. What organically arose as issues of concern were acute trauma and chronic musculoskeletal disorders. The academic researchers felt the committee had the flexibility to address these issues as part of the overall process as long as some attention was given to chemical issues. Although the question of which types of health and safety issues to be focused on did not inhibit the function of the group, it did underscore the tension between a variety of external expectations either imposed upon or brought in by university researchers and the intended nature of AR. It appears that the reason this situation did not become problematic, unlike the issue of the "baseline" survey, was the UM researchers' ability to be flexible and follow the lead of the committee in addressing the areas of greatest concern.

Finally, a challenge the UM researchers faced was the lengthy period needed to select an appropriate site for the AR project. Although the process of careful selection of a suitable site and negotiation with representatives at that site in launching an AR process was extremely time consuming, it was essential to a reasonable probability of success in implementing AR within this industrial context. In fact, the ability to identify and successfully negotiate at a facility where both key management and key union personnel appeared to have significant interest in considering a AR process addressing health and safety contributed fundamentally to the eventual success of the project. Even in the context of unequal power relationships, the basic trust of management and union leadership that they both shared the goals of reducing employee illness and injury contributed fundamentally to the ability of the project to produce successes.

\section{Lessons Learned}

Some lessons can be derived from these many challenges. Firstly, context can have extensive influence on AR projects to address occupational health and safety, especially those that aim to alter organizational culture. Establishing an AR committee does not immediately change the underlying power dynamics in a plant. Introduction of a new way of doing business and making decisions is a fragile process, which depends on the support of influential figures within the plant. Individual and group dynamics can also affect the AR process and thus need to be effectively managed.

A second lesson concerns communication, the data gathering process, and associated time pressures. Initially, the importance of data collection on health and safety attitudes and conditions as a tool for decision-making to lead to more successful interventions was not sufficiently stressed at this facility. Perhaps if researchers had initially placed more emphasis on the need for and usefulness of data gathering, group members may have been more willing to adjust the time schedule of the HAZCOM training to accommodate questionnaire development. This type of systematic data collection, analysis, and interpretation at first struck most committee members as a foreign concept. Eliciting the committee's ideas about data collection, sharing the results with the committee, and encouraging the committee to think about ways to use the results might have helped overcome opposition. Over time, UM researchers grew better at communicating and the committee gained a better understanding of the importance of data collection.

Improved communication among the UM researchers might also have helped with the challenges concerning roles. Members of research teams need to engage in explicit, detailed discussions about roles and responsibilities prior to initiating an AR project and continue these discussions throughout the project.

Flexibility of both researchers and committee members is a key element of AR. Structures and processes developed by participatory groups need to allow for adaptability to respond to changing circumstances. Nevertheless, the integrity of the group's focus should not be compromised in the effort to maintain adaptability. Finally, researchers considering adopting an AR method should be aware that a potentially large time investment may be needed to find an appropriate site and that the AR process can be difficult to explain to those unfamiliar with it.

\section{CONCLUSIONS}

$\mathrm{AR}$ is a long-term process. The changes achieved by AR projects are often of an incremental nature. Although it is unrealistic to expect that immediate large-scale change will result simply from establishing an AR committee, small initial improvements can be achieved which culminate in a safer working environment. In this project, committee members came to recognize the value of the process of collecting and analyzing data, taking action, and recording experiences for future reference. A consensus had to be built and trust had to be established between union and management. Union members of the group, who previously had never talked to management during a meeting, began to make presentations and facilitate. A shift occurred from an adversarial way of dealing with health and safety issues to a more cooperative one. Despite various challenges, in its first 6 months the AR committee completed several objectives including: (1) made suggestions for ergonomic improvements and scheduled training; (2) arranged for HAZCOM training; (3) recognized the need for data collection and 
analysis, so that informed decisions could be made; and (4) developed communication and facilitation skills of group members.

This study provides a model for AR implementation initiated by university-based researchers in a unionized workplace. In this instance, the UAW was instrumental in providing entry to a workplace for an academic-initiated AR process focused on health and safety. Even though, the UAW is a progressive union with a well-established health and safety department providing technical expertise and training resources, it lacked a sufficient level of specific expertise in AR to carry out the process alone. This model of AR implementation is not readily generalizable to the majority of workplaces in the US, which are non-union, nor where such academic groups are not present. Nonetheless, this effort has provided important and useful lessons for future efforts to more widely diffuse knowledge of and the use of $\mathrm{AR}$ as an approach to decision-making in work organizations.

The AR approach requires intensive resources but holds the promise of organizational change within a union represented, automotive parts manufacturing facility. A health and safety AR project requires commitment, dedication, and flexibility on the part of all participants. The results observed and reported in this article have been encouraging, and we believe the process has given employees at this facility a greater sense of ownership over working conditions at their plant. As such, AR has also proven to be not only an effective approach to address occupational health and safety issues, but also a means for building workplace democratization that extends far beyond the life of a specific AR project or university researcher involvement. As one team member put it: "Each individual has placed a stone in the foundation."

Many of the elements central to the AR process can be applied to efforts to change any of a variety of health and safety conditions, from improvements in engineering controls to minimize worker exposure to specific hazardous substances to increased use of hearing protection. The active engagement and joint decision-making of hourly and management representatives will increase the likelihood that the problem will be understood, and that effective solutions will be developed and their application supported and used throughout the organization.

\section{ACKNOWLEDGMENTS}

This research was funded as part of a grant with the International Union of the United Automobile, Agricultural Implement and Aerospace Workers (UAW) from the National Institute of Environmental Health Sciences (NIEHS) Worker Education and Training Program (WETP) grant (NIEHS Grant 5U45ES006180-16). The researchers wish to thank the action research committee members at the participating facility and the staff of the UAW International Health and Safety Department.

\section{REFERENCES}

Bourbaonnais R, Brisson C, Vinet A, Vezina M, Lower A. 2006. Development and implementation of a participative intervention to improve the psychosocial work environment and mental health in an acute care hospital. Occup Environ Med 63:326-334.

Bradbury H, Mirvis P, Nielsen E, Pasmore W. 2008. Action research at work: Creating the future following the path from Lewin. In: Reason P, Bradbury $\mathrm{H}$, editors. The sage handbook of action research: Participative inquiry and practice. Los Angeles; London: Sage, p. 77-92.

Dollard M, Leblanc P, Cotton J. 2007. Participatory action research as work stress intervention. In: Naswall K, Hellgren J, Sverke M, editors. The individual in the changing working life. New York: Cambridge University Press, p. 353-379.

Elden M. 1981. Sharing the research work: Participative research and its role demands. In: Reason P, Rowan J, editors. Human inquiry: A sourcebook of new paradigm research. Chichester [Eng.]; New York: J. Wiley, p. 253-266.

Fernandez JA, Daltuva JA, Robins TG. 2000. Industrial emergency response training: An assessment of long-term impact of a union-based program. Am J Ind Med 38:598-605.

Gardell B. 1982. Worker participation and autonomy: A multilevel approach to democracy at the workplace. Int J Health Serv 12:527-558.

Gardell B, Gustavsen B. 1980. Work environment research and social change: Current developments in Scandinavia. J Occup Behav 1:3-17.

Gaventa J, Cornwall A. 2008. Power and knowledge. In: Reason P, Bradbury $H$, editors. The Sage handbook of action research: Participative inquiry and practice. Los Angeles; London: Sage, p. $172-189$.

Hughes J. 1991. An assessment of training needs for worker safety and health programs: Hazardous waste operations and emergency response. Appl Occup Environ Hyg 6:114-118.

Israel BA, Schurman SJ, House JS. 1989. Action research on occupational stress: Involving workers as researchers. Int J Health Serv 19:135-155.

Israel BA, Schurman SJ, Hugentobler MK. 1992. Conducting action research: Relationships between organization members and researchers. J Appl Behav Sci 28:74-101.

Kowalski R, Yorks L, Jelinek M. 2008. The workplace stress and aggression project: Ways of knowing-our Rosetta Stone for practice. In: Reason P, Bradbury H, editors. The sage handbook of action research participative inquiry and practice. Los Angeles: Sage Publications, p. 497-509.

Kurtz JR, Robins TG, Schork MA. 1997. An evaluation of peer and professional trainers in a union-based occupational health and safety training program. J Occup Environ Med 39:661-671.

Laurell AC, Noriega M, Martinez S, Villegas J. 1992. Participatory research on workers' health. Soc Sci Med 34:603-613.

Lawrence TB, Phillips N, Hardy C. 1999. Watching whale watching: Exploring the discursive foundations of collaborative relationships. J Appl Behav Sci 35:479-502.

Lippin TM, Eckman A, Calkin KR, McQuiston TH. 2000. Empowerment-based health and safety training: Evidence of workplace change from four industrial sectors. Am J Ind Med 38:697-706.

McQuiston TH. 2000. Empowerment evaluation of worker safety and health education programs. Am J Ind Med 38:584-597. 
McQuiston TH, Coleman P, Wallerstein NB, Marcus AC, Morawetz JS, Ortlieb DW. 1994. Hazardous waste worker education: Long-term effects. J Occup Med 36:1310-1323.

Mikkelsen A, Gundersen M. 2003. The effect of a participatory organizational intervention on work environment, job stress, and subjective health complaints. Int J Stress Manage 10:91-110.

Mikkelsen A, Saksvik PÃ, Landsbergis P. 2000. The impact of a participatory organizational intervention on job stress in community health care institutions. Work Stress 14:156-170.

Occupational Safety and Health Administration. 2003. 29 CFR 1910. 1200.

Parkes K, Sparkes T. 1998. Organizational interventions to reduce work stress. Are they effective? Contract Research Report. Oxford: University of Oxford, p. 52.

Reason P, Bradbury W. 2001. Introduction: Inquiry and participation in search of a world worthy of human aspiration. In: Reason P, Bradbury H editors. Handbook of action research: Participative inquiry and practice. London; Thousand Oaks, CA: Sage, p. 1-26.

Ryan G, Bernard H. 2000. Data management and analysis methods. In: Denzin N, Lincoln Y, editors. Handbook of qualitative research. Thousand Oaks: Sage, p. 769-802.

Schulz AJ, Israel BA, Lantz P. 2003. Instrument for evaluating dimensions of group dynamics within community-based participatory research partnerships. Eval Program Plann 26:249.

Schurman S, Israel B. 1995. Redesigning work systems to reduce stress: A participatory action research approach to creating change. In: Murphy
L, Hurrell JJ, Jr., Sauter S, Keita G, editors. Job stress interventions: Currrent practices and new directions. 1st edition. Washington, DC: American Psychological Association, p. 235-263

Simon E. 2006. Diminishing returns: Auto workers' power wanes. Arizona Daily Star.

Svensson L. 1991. A democratic strategy for organizational change. In: Gardell B, Johnson JV, Johannson G, editors. The psychosocial work environment: Work organization, democratization, and health: Essays in memory of Bertil Gardell. Amityville; NY: Baywood Pub, p. 241256.

University of Michigan Evaluation Group. 1992. Follow-up impact evaluation report: A case study of workers at one site who attended a UAW hazardous materials emergency response awareness training program. Ann Arbor: University of Michigan, School of Public Health.

University of Michigan Evaluation Group. 1995. A case-study evaluation of a joint safety committee: Accomplishments, effectiveness and impact. Ann Arbor: University of Michigan, School of Public Health.

Vangen S, Huxham C. 2003. Nurturing collaborative relations: Building trust in interorganizational collaboration. J Appl Behav Sci 39:531

Wallerstein N, Weinger M. 1992. Health and safety education for worker empowerment. Am J Ind Med 22:619-635.

Whyte WF. 1991. Participatory action research. Newbury Park, CA Sage, p. 247. 